\title{
The Origin of Turtles: A Paleontological Perspective
}

\author{
WALTER G. JOYCE* \\ Department of Geoscience, University of Fribourg, Fribourg, Switzerland
}

\begin{abstract}
The origin of turtles and their unusual body plan has fascinated scientists for the last two centuries. Over the course of the last decades, a broad sample of molecular analyses have favored a sister group relationship of turtles with archosaurs, but recent studies reveal that this signal may be the result of systematic biases affecting molecular approaches, in particular sampling, non-randomly distributed rate heterogeneity among taxa, and the use, and the use of concatenated data sets. Morphological studies, by contrast, disfavor archosaurian relationships for turtles, but the proposed alternative topologies are poorly supported as well. The recently revived paleontological hypothesis that the Middle Permian Eunotosaurus africanus is an intermediate stem turtle is now robustly supported by numerous characters that were previously thought to be unique to turtles and that are now shown to have originated over the course of tens of millions of years unrelated to the origin of the turtle shell. Although E. africanus does not solve the placement of turtles within Amniota, it successfully extends the stem lineage of turtles to the Permian and helps resolve some questions associated with the origin of turtles, in particular the non-composite origin of the shell, the slow origin of the shell, and the terrestrial setting for the origin of turtles.
\end{abstract}

The origin of turtles and their unusual body plan remain some of the most vexing questions in vertebrate evolution. The debate is unusually complex as it involves several interrelated issues, in particular, the relationship of turtles relative to extant amniotes (e.g., Zardoya and Meyer, '98; Tzika et al., 2011; Field et al., 2014), the closest fossil relatives of turtles (e.g., Laurin and Reisz, '95; deBraga and Rieppel, '97; Lee, '97; Carroll, 2013), the placement of the shoulder girdle (Nagashima et al., 2009, 2013; Lyson and Joyce, 2012), the origin of the turtle shell (e.g., Burke, '89; Nagashima et al., 2007; Scheyer et al., 2008; Joyce et al., 2009; Lyson et al., 2013a), the speed of the origin of the turtle shell (e.g., Rieppel, 2001; Joyce et al., 2009), and the ecological settings for the origin of turtles (e.g., Rieppel and Reisz, '99; Joyce and Gauthier, 2004; Scheyer and Sander, 2007). The recent discovery of the intermediate fossil taxon Odontochelys semitestacea from the Late Triassic of China (Li et al., 2008) sheds much light on some aspects of this discussion as it clearly is situated outside the previously recognized turtle clade Testudinata (herein defined as the clade originating from the first amniote with a fully developed turtle shell [sensu Joyce et al., 2004] consisting of interlocking neurals, costals, peripherals, pygals, and plastral elements [Gaffney and Meylan, '88]). Most importantly, this taxon reveals that the origin of the turtle shell occurred through the novel interaction of the dorsal vertebrae and ribs, the shoulder girdles, and perhaps also the gastralia with the dermis, as had been predicted for years by developmental biologists (e.g., Zangerl, '39; Burke, '89; Gilbert et al., 2001), and not through the fusion of these elements with osteoderms, as had largely been favored by paleontologists (e.g., Cox, '69; Lee, '97; Joyce et al., 2009). The funding of 0 . semitestacea, furthermore, spawned renewed interest in the old hypothesis (Watson, '14) that turtles may be related to the Permian taxon Eunotosaurus africanus (Carroll, 2009; Lyson et al., 2010, 2013a, 2014). However, while the hypothesis that the Middle Triassic 0 . semitestacea is a derived stem turtle has been universally accepted (e.g., Nagashima et al., 2009; Kuratani et al., 2011; Anquetin, 2012; Nagashima et al., 2012, 2013; Hirasawa et al., 2013, 2014), likely because of the presence of a fully developed plastron, the reinterpretation of the Late Permian E. africanus as an

*Correspondence to: Walter G. Joyce, Department of Geoscience, University of Fribourg, Fribourg, Switzerland.

E-mail: walter.g.joyce@gmail.com 
intermediate stem turtle is less quickly gaining acceptance (e.g., Kuratani et al., 2011; Nagashima et al., 2012, 2013; Hirasawa et al., 2013, 2014). This reluctance likely stems from a series of misconceptions about amniote systematics and the fossil record, in particular, the remaining ambiguity regarding the phylogenetic position of turtles. The purpose of this contribution is therefore to clear up these misconceptions and to summarize the mounting evidence in favor of E. africanus as an intermediate stem turtle.

\section{THE TRADITIONAL CLASSIFICATION OF FOSSIL REPTILES USING TEMPORAL FENESTRAE IS OUT OF DATE}

Williston ('17) published a fundamental treatment of the phylogeny and classification of amniotes based on Osborn's ('03) work on temporal fenestration that was highly influential for many decades. The basis of this classification was the number of openings in the temporal region of the skull. According to Williston's classification, taxa that lack temporal fenestrae are grouped as Anapsida (e.g., turtles, various basal reptiles), taxa with a pair of upper temporal fenestrae as Parapsida (a.k.a. Euryapsida; e.g., ichthyosaurs and squamates), taxa with a pair of lower temporal fenestrae as Synapsida (e.g., mammals), and taxa with two pairs of temporal fenestrae are grouped as Diapsida (e.g., crocodilians, Sphenodon). The most influential new statement under Williston's model is that the anapsid condition is primitive, and that turtles are consequently to be considered the most primitive of living amniotes. Most subsequent authors followed Williston's model and placed "anapsid" tetrapods from the Permian and Triassic as the "direct ancestors" to turtles, such as pareiasaurs (Gregory, '46), diadectids (Olson, '47), or "captorhinomorphs" (Carroll, '69).

Although the temporal region provides important phylogenetic information for amniote phylogeny, the last decades of research have shown that Williston's ('17) system is far too simplistic, because many formerly homogenous groups were shown to exhibit multiple conditions (e.g., Dilkes, '98; Rieppel, 2000b; Tsuji and Müller, 2009) and because phylogenetic analyses have shown that the number of temporal fenestrae changed multiple times throughout amniote evolution (e.g., Müller, 2003). The possible placement of anapsid turtles within crown Diapsida only underlines this point, as it implies the secondary loss of both temporal fenestrae (Rieppel and deBraga, 1996; Rieppel, 2000a), a conclusion already proposed by early opponents to the Williston model (Broom, '24; Goodrich, '30; deBeer, '37) and readily accepted by those favoring this phylogenetic arrangement. However, even if turtles evolved from diapsid ancestors, there is no reason to believe a priori that the loss of both temporal fenestrations occurs in synchrony with the acquisition of the turtle shell. The early stem lineage of turtles is therefore expected to potentially be populated with taxa with the diapsid condition. Fenestration alone is, therefore, not a strong argument for or against the placement of Eunotosaurus africanus, or any other taxon, along the stem lineage of turtles.

\section{MOLECULAR RESULTS MAY BE AFFECTED BY SYSTEMATIC BIASES}

The discussion regarding the origin of turtles has been dominated over the course of the last 20 years by phylogenetic hypotheses obtained from molecular data and I herein only intend to provide a brief overview. The first decade of molecular research did not provide consistent results for amniote phylogeny and turtles were variously placed as sister to Aves (Pollock et al., 2000; Cotton and Page, 2002), Crocodilia (Hedges and Poling, '99; Mannen and Li, '99; Cao et al., 2000), Diapsida (e.g., Caspers et al., '96; Strimmer and von Haeseler, '96), Lepidosauria (Hedges, '94), Thecodontia (i.e., Mammalia + Archosauria, Gardiner, '93), or Archosauria (e.g., Platz and Conlon, '97; Cao et al., '98; Zardoya and Meyer, '98; Kumazawa and Nishida, '99; Rest et al., 2003). Over the course of the second decade, however, the vast majority of analyses utilizing molecular data supported a sister group relationship of turtles to archosaurs using a broad range of data and analytical techniques (e.g., Iwabe et al., 2005; Hugall et al., 2007; Shen et al., 2011; Chiari et al., 2012; Crawford et al., 2012; Fong et al., 2012; Abramyan et al., 2013; Schaffer et al., 2013; Wang et al., 2013), although occasional support was also found for a sister group relationship with crocodilians (e.g., Shedlock et al., 2007; Tzika et al., 2011). The only major molecular study to arrive at a truly conflicting result in the last 10 years was the study of Lyson et al. (2012) utilizing microDNA data, but the recent expansion and reanalyses of this data set by Field et al. (2014) and Thomson et al. (2014) retrieved archosaurian affinities as well. Molecular analyses are, therefore, converging upon a turtle and archosaur relationship.

Some of the greatest concerns for all types of systematics are referred to as "systematic biases." One of the first such biases to be discovered is also one of the most intuitive to understand. Felsenstein ('78) noted that parsimony methods will retrieve the wrong result in a four-taxon system, if two unrelated branches are significantly longer than the others, because randomly accumulated homoplasy in the long branches will wrongfully serve as synapomorphies (i.e., secondary homologies sensu de Pinna, '91), an effect referred to as long-branch attraction. Most vexingly, the addition of data does not solve this problem, but rather amplifies it, thereby producing greater confidence for the wrong result (Felsenstein, '78). Taken to the extreme, the use of the total genomes will not solve problems associated with longbranch attraction, but only compound them.

Although the consistent signal being retrieved from increasingly diverse sets of molecular data is impressive, the persistent morphological signal against the archosaurian relationships of turtles (e.g., Reisz and Laurin, '91; deBraga and Rieppel, '97; Lee, '97; Müller, 2004; Lyson et al., 2010; Lee, 2013; see below) combined with the complete lack of a morphological signal in support of the archosaur hypothesis (Rieppel, 2000a; Lyson et al., 2010), despite earnest attempts to find some (Bhullar and Bever, 2009), gives reasons to speculate if molecular hypothesis are 
perhaps converging upon the same result because of a systematic bias. Three partially interrelated biases come to mind that might be relevant to this particular phylogenetic conundrum: sampling, rate heterogeneity, and the use of concatenated data sets.

Sampling is of enduring importance in systematics (e.g., Lecointre and Philippe, '93; Graybeal, '98; Hillis, '98; Rannala et al., '98) because the inclusion of intermediate morphologies or genotypes helps avoid a broad set of systematic biases, including the above-mentioned long-branch attraction (Gauthier et al., '88b; Donoghue et al., '89). However, whereas paleontologists at least have the potential to sample all of life, despite massive taphonomic filters (Benton et al., 2000), molecular systematists can only sample extant taxa, or at best newly extinct taxa (Nicholls, 2005). This issue is compounded by the fact that extant taxa do not sample the Amniote tree at random, but rather as eight discrete clades (i.e., Aves, Crocodilia, Monotremata, Marsupialia, Placentalia, Squamata, Sphenodon, and Testudines) that diversified within the last $100 \mathrm{Ma}$ and that are interconnected by lineages spanning many hundreds of millions of years (e.g., Wang et al., 2013). Significant portions of the tree, in particular, the stem lineages of various clade combinations, are therefore inherently out of reach for molecular systematists and must be modeled. The fact that the three primary lineages of reptiles likely diversified from one another within a short time in the middle to late Permian (Wang et al., 2013) does not make matters easier for systematists using neontological data alone.

Varying rates of molecular evolution may be the basis of yet another systematic bias. Although rates of molecular evolution have been shown to be variable across the tree, all molecular methods rely at least partially on a certain amount of rate homogeneity among lineages (e.g., Philippe et al. 2005). Unfortunately, rates do not vary at random across the tree, but rather have a strong taxonomic signal as well. For instance, the study of Hugall et al. (2007) revealed that crocodilians and turtles showed the slowest rate of molecular evolution among tetrapods, while passerine birds and snakes, among others, show some of the fastest rates. It is therefore possible that the rate-averaging effect of various molecular methods pulls taxa with slow rates towards the tips of the tree, or towards one another, while pushing taxa with fast rates towards the base of the tree. Indeed, most taxa with controversial phylogenetic relationships (see Gauthier et al., 2012; for examples within Lepidosauria) display deviant rates of molecular evolution (Hugall et al., 2007).

The vast majority of recent molecular analyses of turtle relationships used concatenated data (i.e., a super matrix approach using sequence data from 100s to 1000s of genes). This approach is utilized regularly, as it allows incorporation of the greatest amount of data, but studies have shown that it is prone to systematic error as well (e.g., Nishihara et al., 2007; Salichos and Rokas, 2013). Using one of the largest data sets assembled to date, Lu et al. (2013) recently evaluated the phylogenetic signal contained in 4,584 orthologous genes separately and arrived at the surprising conclusion that the three primary placements of turtles (i.e., as sister to Diapsida, Lepidosauria, or Archosauria) are supported by roughly the same number of genes, and that an archosaurian signal emerges only through the concatenation of the data. From a molecular perspective, turtles, archosaurs, and lepidosaurs, therefore, seem to form a hard polytomy (Lu et al., 2013), likely due to their rapid diversification, and the recent trend towards recovering archosaurian sister group relationships for turtles may be the result of rate heterogeneity in combination with the use of concatenated data.

There only is one tree of life and it is apparent that either the molecular or the morphological signal is wrong. As outlined above, there are good reasons to seriously entertain the idea that the molecular data may possibly be converging on the wrong answer due to systematic biases associated with sampling, rate heterogeneity, and the use of concatenated data. Future molecular studies should therefore focus their efforts on identifying sequence data relevant to resolving divergences that occurred during the late Paleozoic and calibrate rate heterogeneity through the use of fossils. The traditional focus on obtaining ever-increasing amounts of sequence data from extant taxa is not sufficient any longer (Philippe et al., 2011). Until these points have been addressed, the debate regarding the placement of turtles within Amniota remains far from over.

\section{STEM-TURTLES CAN BE IDENTIFIED WITHOUT UNDERSTANDING THE PLACEMENT OF TURTLES}

In contrast to molecular systematists, paleontologists not only have the ability to investigate the placement of turtles among extant amniotes, but also the organisms that populate the stem lineage of turtles (i.e., the phylogenetic lineage of extinct organisms that leads to the modern turtle clade). However, it is not necessary to understand the placement of turtles within the amniote system to assign fossils to their stem lineage with confidence. For instance, recent cladistic analyses have assigned a broad sample of shelled amniotes from the Late Triassic (e.g., Proterochersis robusta, Proganochelys quenstedti, Palaeochersis talampayensis) to the Pleistocene (e.g., Meiolania platyceps) to the stem lineage of turtle (e.g., Joyce, 2007; Anquetin, 2012; Sterli et al., 2013) and these results have been uncontroversial in regards to the placement of these taxa within Testudinata (e.g., Gaffney et al., 2007; Joyce and Sterli, 2012; Joyce et al., 2013a), even though none of these studies utilized global amniote matrices. The reason for this lack of controversy is, of course, the presence of fully developed turtle shells in all of these taxa, a "key-character" assumed to have great weight (Joyce and Sterli, 2012).

Li et al. (2008) used a global matrix to assign Odontochelys semitestacea to the stem lineage of turtle and Lyson et al. (2010) utilized the same matrix to assign Eunotosaurus africanus to the stem lineage as well. Interestingly, whereas the analysis of Li et al. (2008) places turtles along the stem of Lepidosauria, not Archosauria, 
the analysis of Lyson et al. (2010) hypothesized that turtles are outside of Diapsida. However, is the hypothesis that E. africanus is a stem turtle contingent upon the placement of the entire clade outside of Diapsida? Is it possible that E. africanus is a stem turtle, but that turtles are nevertheless sister to archosaurs or lepidosaurs?

In a recent study, Lee (2013) explored this question by retrofitting turtles and Eunotosaurus africanus to previouslypublished morphological data sets with contradictory outcomes in regards to turtle origins. In all analysis, E. africanus was placed as sister to turtles at the base of the reptilian tree, much as already noted by Lyson et al. (2010), thereby giving additional credence to the notion that E. africanus is a tree changing taxon (see sampling above). In the next analysis, Lee (2013) forced turtles as sister to archosaurs, as supported by the abundant molecular data (see above), and noticed that this arrangement only requires the addition of few steps. More importantly, however, even though E. africanus was allowed to float in all analyses, also those with forced topologies, it consistently was retrieved as a stem turtle.

The analysis of Lee (2013) is important for two reasons. It first demonstrates that two competing morphological analyses with different taxonomic focuses (i.e., deBraga and Rieppel, '97 [with modification from Rieppel and Reisz, '99; Li et al., 2008; Lyson et al., 2011; and Lee, 2013] and Müller and Tsuji, 2007 [with modifications from Modesto et al., 2009; Tsuji et al., 2010, 2012; and Lee, 2013]) converge on the placement of turtles outside of crown Diapsida, but that this result may not be statistically significant relative to other solutions. The morphological signal is therefore not able to resolve the placement of turtles within amniotes for the moment, just like the molecular data, perhaps because of a sampling bias, or perhaps because the three major reptilian lineages diverged from one another very rapidly during the Late Paleozoic, the same two biases effecting molecular data. The analysis of Lee (2013), secondly, reveals that the interpretation of E. africanus as an intermediate stem turtle is highly robust, relatively immune to perturbances, and that this placement is independent from the placement of turtles within Amniota. So, even though morphology cannot resolve the placement of turtles within amniotes with great confidence either, the signal referring $E$. africanus to the stem lineage of turtles is strong and cannot be flippantly brushed aside. This contrasts the placement of sauropterygians along the stem lineage of turtles, which has only been supported by a single analysis (deBraga and Rieppel, '97, and some of the following studies utilizing this matrix), but is easily perturbed through the addition of new taxa and/or characters (Rieppel and Reisz, '99; Lyson et al., 2011; Lee, 2013). All studies that utilize sauropterygians as model organisms for the origin of turtles therefore lack a solid phylogenetic footing.

\section{THE EUNOTOSAURUS HYPOTHESIS}

In the type description of Eunotosaurus africanus, Seeley ('92) already compared the number of dorsal vertebrae, the elongate shape of the dorsal vertebrae, and the expanded ribs found in this taxon with those of turtles, but hesitated from placing it along the stem lineage of turtles. Watson ('14) later reinvestigated $E$. africanus based on additional material and expanded the list of possible synapomorphies to include the purported presence of 10 elongate dorsal vertebrae (actually 9, see below) that are much longer than the cervicals and caudals, the purported presence of 8 expanded ribs (actually 9, see below), an anterior shift of the dorsal ribs relative to the dorsal vertebrae, and the purported presence of dermal ossifications (not confirmed to be present in later studies, Lyson et al., 2013). Many years later, Parsons and Williams ('61) dismissed a relationship of E. africanus with turtles, because the ribs of modern turtles, as seen in marine turtles with reduced costals, are purportedly not as wide as those of E. africanus. This assessment was not only incorrect (see below) but also had far reaching effects, as most following authors disregarded the Eunotosaurus hypothesis completely.

The discovery of Odontochelys semitestacea (Li et al., 2008) immediately renewed interest in a potential link of E. africanus with turtles (Carroll, 2009), because 0 . semitestacea bridges the apparent morphological gap between E. africanus and true turtles (i.e., amniotes with a full turtle shell). A link has since been formally proposed (Lyson et al., 2010) and backed up by a series of additional studies (Lyson and Joyce, 2012; Lee, 2013; Lyson et al., 2013a,b, 2014). The list of unique characters that unite E. africanus with 0 . semitestacea and turtles has grown to be impressive (Fig. 1). For simplicity I will discuss these in anatomical groups, even though they could be further anatomized:

Dorsal Vertebral Count/Elongation of Dorsal Vertebrae Relative to Other Vertebrae

As already noted by Seeley ('92) and Watson ('14), Eunotosaurus africanus can be united with turtles based on dorsal vertebral count and elongation of the dorsal vertebrae relative to surrounding parts of the body. The number of vertebrae varies greatly among vertebrates, but such an extreme reduction is unique to these taxa (Müller et al., 2010). More importantly, whereas the reduction in vertebral number in most taxa is correlated with a shortening of the dorsal column, E. africanus, o. semitestacea, and turtles show a unique elongation of these vertebrae relative to the surrounding regions. This trend is only reversed in some modern turtles after the acquisition of extreme neck mobility (Werneburg et al., 2014).

Modern turtles universally have 10 dorsal ribs, of which the first and tenth are greatly shortened and the second to ninth form costals (i.e., ribs that interact with the dermis to form a composite with metaplastic bone, more details below). The most primitive turtles with a well-preserved shell, such as Proganochelys quenstedti or Proterochersis robusta, also reveal the presence of 10 dorsal ribs, but the first is greatly elongated, like the last cervical, whereas the remaining nine form costals (Gaffney, '90, 


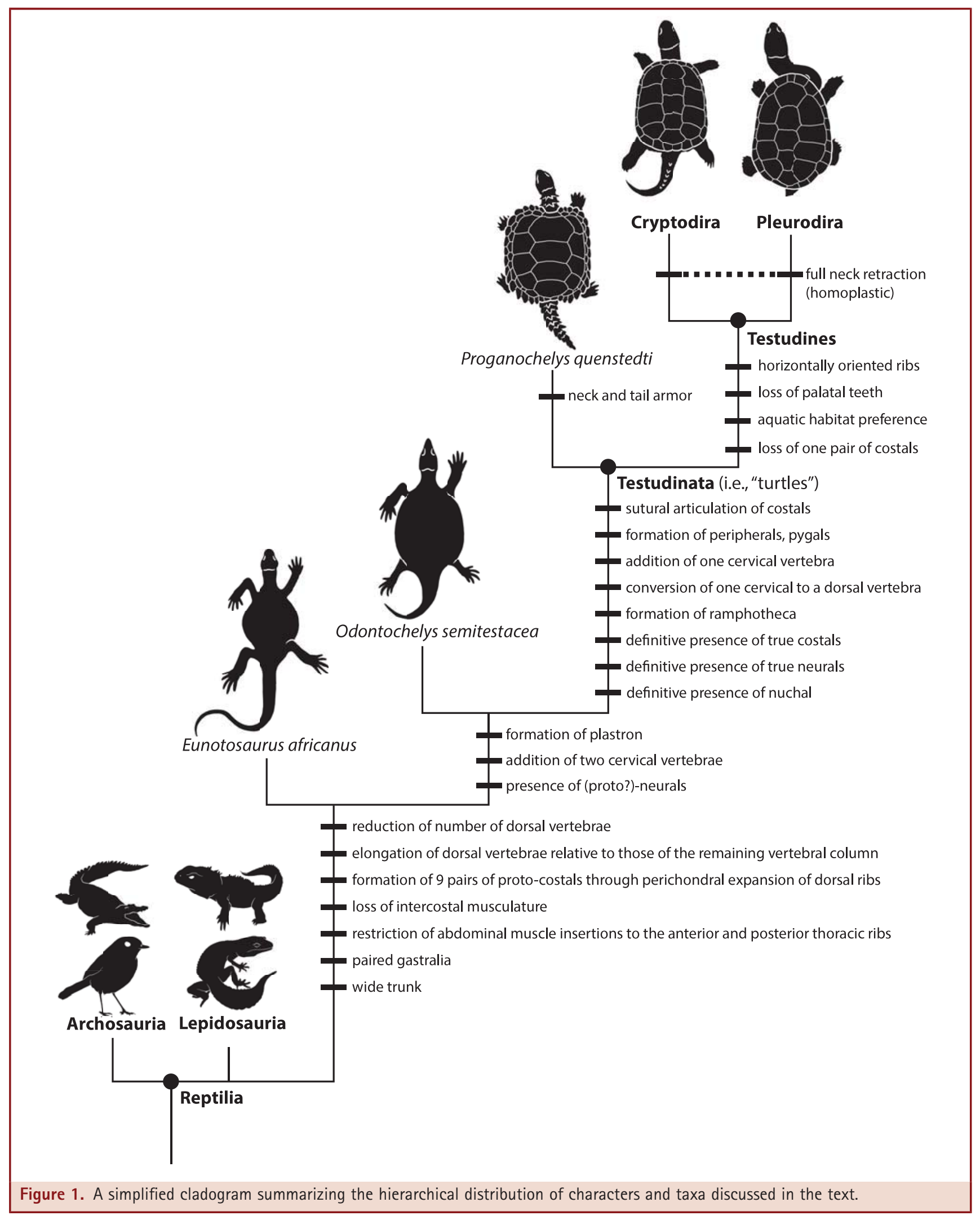


fig. 75; Joyce, 2007; Joyce et al., 2013a). The cervical-like nature of the first thoracic vertebra and rib of basal turtles is striking (Gaffney, '90, fig. 108) and it is possible that this vertebra is a cervical that was "captured" by the shell. Once this "dorsalized" vertebra is removed from consideration, the basal condition of turtles overlaps with that found in Odontochelys semitestacea (Li et al., 2008) and E. africanus (Lyson et al., 2013a) in regards to the number of dorsal vertebrae and ribs. The only apparent disparity between these groups pertains to the number of cervical vertebrae (Li et al., 2008; Lyson et al., 2013a), and it is necessary to postulate the addition of two cervical vertebrae from E. africanus to $O$. semitestacea and the addition of yet another cervical vertebra and the capture of the most posterior cervical by the shell from 0 . semitestacea to Testudinata (Fig. 1). I speculate that the acquisition of additional cervical vertebrae is likely linked to the origin of the turtle shell, which demanded the acquisition of a more elongate and flexible neck to compensate for the extreme stiffening of the truck (Werneburg et al., 2014). The loss of the most posterior costal at the base of crown Testudines is already well documented by numerous phylogenetic studies (e.g., Gaffney et al., '91; Joyce, 2007).

Dorsal Ribs Expanded by Perichondral Outgrowths and Metaplastic Bone

Seeley ('92) and Watson ('14) already highlighted the presence of expanded ribs as a potential, diagnostic synapomorphy between E. africanus and turtles, but this character was later dismissed by Parsons and Williams ('61) because the ribs of modern turtles appear to be less expanded that those of E. africanus. The latter conclusion, however, was misguided because Parsons and Williams ('61) failed to distinguish between the rib portion and the metaplastic outgrowths of the ribs in both taxa.

Although paleontological data now clearly reject the traditional hypothesis that the costals of turtles are the result of an evolutionary fusion of the ribs and overlying osteoderms (Li et al., 2008), these bones are nevertheless composites formed through the expansion of the rib into the skin through perichondral and metaplastic outgrowths (e.g., Scheyer et al., 2008). Embryological studies reveal that the ribs grow into the dermis during ontogeny, initially through an expansion of the rib's perichondral collar, and then through the metaplastic ossification of the overlying (Hirasawa et al., 2013; fig. 2) or surrounding (Scheyer et al., 2008; fig. 2) dermal tissue. Accordingly to some definitions, the perichondral and metaplastic portions of the costal should be considered to be "appositional bone" (Patterson, '77) or "Zuwachsknochen" (Starck, '55) and the entire costal could therefore be regarded to be endoskeletal in nature (Rieppel and Reisz, '99). I find this point to be semantic at best and misleading at worst, because the categorization of the entire costals as purely endoskeletal unnecessarily downplays the role of the dermis in the formation of these bones. I herein distinguish clearly between the original endochondral portions of the rib versus the appositional, perichondral and metaplastic portions of the rib. I also call any rib with perichondral outgrowths a proto-costal and a rib with perichondral and metaplastic outgrowths a costal and similarly term any (still hypothetical) dorsal vertebra with perichondral outgrowths a proto-neural and a dorsal vertebra with perichondral and metaplastic outgrowths a neural.

Parsons and Williams ('61) originally observed that the endochondral ribs of modern turtles are significantly narrower than the overlying metaplastic bone, which is most apparent in many juvenile and various aquatic turtles, where the distal portions of the ribs are not covered by metaplastic bone. These authors, however, erred by presuming that the broadened elements of $E$. africanus consist only of the rib and lack perichondral or metaplastic outgrowths. This assumption does not appear to be false at first look, because the expanded ribs of most amniotes consist of endochondral bone only. However, Lyson et al. (2013a) recently revealed that the expanded ribs of $E$. africanus actually consist of a vertically oriented endochondral rib and horizontally expanded perichondral outgrowths of the ribs (Lyson et al., 2013a, figs. 2, 3), a character previously thought to be unique to turtles (Scheyer et al., 2008). Although Li et al. (2008) state that 0 . semitestacea lacks costals, it is apparent from the images accompanying the type description (Li et al., 2008, figs. 1,3 ) that the costals are T-shaped in cross section (Lyson et al., 2010). However, only histological analysis will reveal whether this taxon possessed proto-costals or true costals. It is similarly unclear if the midline of 0 . semitestacea possessed proto-neurals or true neurals. Only testudinates are therefore known to have true costals and true neurals, as defined herein (Fig. 1).

The costals of E. africanus differ primarily from those of crown turtles by having vertically oriented ribs and by lacking sutural contacts (Lyson et al., 2013, figs. 1, 2), but this morphological gap is bridged by Odontochelys semitestacea, which lacks sutural contacts between the costals (Li et al., 2008, fig. 1), and numerous stem turtles that possess vertically oriented ribs as well (Gaffney, '90, fig. 81; Joyce et al., 2009, fig. 1, Joyce et al., 2013a, fig. 2). The only major transitions within this character complex, therefore, occur within the known turtle stem lineage (Fig. 1).

The realization that E. africanus possesses expanded ribs that are structurally equivalent with those of turtles is particularly significant, because it corroborates predictions made by embryological studies as to the origin of these structures (Lyson et al., 2013a).

\section{The Turtle Breathing Apparatus}

Extant amniotes exhibit a broad range of breathing mechanisms, but all groups show some type of costal ventilation (i.e., breathing through the expansion and contraction of the ribcage). Turtles are the notable exception to the rule, because the formation of the shell precludes movement between the ribs. Instead, turtles rely on a unique system formed by two pairs of antagonistic 
abdominal muscles, the M. transversus and M. obliquus abdominis (Gaunt and Gans, '69; Brainerd and Owerkowicz, 2006). Paleontologists have puzzled over the origin of this breathing mechanism (Rieppel and Reisz, '99), but few insights have been produced on how this breathing system might have originated.

A recent study by Lyson et al. (2014) demonstrated that the presence of intercostal muscles can be traced in osteological specimens with confidence by tracing the fibers muscles leave behind in bone at their insertion points using histological sections. This discovery is important, as it allows the reconstruction of the breathing apparatus of extinct organisms with confidence. Lyson et al. (2014) also showed that turtles are the only extant amniotes known to have fully lost their intercostal musculature at post-hatching stage, but also that all groups of extant amniotes with broadened ribs (e.g., ant eaters, loris, tree shrews) exhibit reduced amounts of intercostal musculature (Jenkins, '70). It therefore seems to be universally true in amniotes that the rib cage is most commonly stiffened through an expansion of the ribs, which in return results in a reduction of intercostal breathing and the necessity to explore alternative modes of breathing. In turtles this conundrum was solved through the specialization of the abdominal muscles. As Lyson et al. (2014) note, these muscles symplesiomorphically attach to the visceral side of all dorsal ribs in other amniotes, but are constricted to the anterior and posterior dorsal ribs in turtles, but not the middle dorsal ribs. Incidentally, the points of insertion of the abdominal muscles can also be traced with confidence in histological sections of the ribs and it is therefore possible to reconstruct the origin of the turtle breathing apparatus in the fossil record.

In a final step, Lyson et al. (2014) analyzed the expanded ribs of Eunotosaurus africanus and arrived at the surprising conclusion that this taxon (1) lacks intercostal muscles and (2) that the insertion site for the abdominal muscles are restricted to the anterior and posterior dorsal ribs, and are lacking in the middle dorsal ribs. All osteological correlates for the unique turtle breathing system are therefore to be found in E. africanus as well. This highly surprising result provides unusually strong support for the phylogenetic relationships of E. africanus with turtles (Fig. 1).

Turtles are linked to Eunotosaurus africanus by a number of additional characters, but these lack the same weight as those outlined above, because they either are not exclusive to these taxa, or represent reptilian symplesiomorphies, or are based on difficult homology assessments. These include, among others, the presence of paired gastralia lacking lateral and medial elements (present among numerous parareptiles, Lyson et al., 2013a), the symplesiomorphic presence of cleithra (Lyson et al., 2013a, b; not sensu Joyce et al., 2006), cranial tubercles (Lyson et al., 2012; also present in a broad sample of amniotes), and a wide trunk (Lyson et al., 2012; also present in a broad sample of amniotes). A recent reevaluation of the should girdle of turtles reveals that the scapula is not located within the rib cage, as often erroneously reported, but rather anterior to the rib cage (Lyson and Joyce, 2012). This arrangement is hardly unique, however, as it broadly occurs among basal amniotes and therefore demands no special explanation (Lyson and Joyce, 2012). Given the absence of neck and tail armor in 0 . semitestacea, their presence in Proganochelys quenstedti and Chinlechelys tenertesta is now best interpreted as a derived synapomorphy of these two taxa only, not a basal symplesiomorphy of Testudinata (contra Joyce et al., 2009). Finally, recent investigations have shown that the hooked element in the pes of turtles is a composite structure formed by the fifth distal tarsal and the fifth metatarsal, but the homology of structure with similar hooked elements in other reptiles remains unclear for the moment (Joyce et al., 2013b).

\section{THE ORIGIN OF TURTLES OCCURRED ON LAND}

The purported ecology of the origin of turtles has historically been used to support various phylogenetic scenarios, as a sister group relationship with various terrestrial groups of vertebrates implies a terrestrial origin of the group, whereas a close relationship with aquatic groups implies an aquatic origin (Joyce and Gauthier, 2004). Five lines of evidence have been developed in the last decade to support the terrestrial nature of the earliest turtles (i.e., taxa at the base of the clade Testudinata). First, basal turtles universally have a reduced phalangeal count (e.g., Gaffney, '90, '96; Sterli et al., 2007) and/or short hands, characters that correlated with terrestrial habitat preferences today (Joyce and Gauthier, 2004). Second, many basal turtles known from complete skeletons are known to have osteoderms (e.g., Gaffney, '90; Joyce et al., 2014), another feature only found among terrestrial turtles today (Joyce and Gauthier, 2004). Third, at least two lineages of basal turtles have tail clubs (e.g., Gaffney, '90, '96), which are defensive features that cannot be utilized under water (Joyce and Gauthier, 2004). Fourth, the shell bone histology of basal turtles shows characteristics otherwise typically found among modern terrestrial turtles (Scheyer and Sander, 2007). And finally, despite a global preponderance of marine and freshwater aquatic faunas from the Triassic, basal turtles are universally found in terrestrial sediments and associated with terrestrial faunas, particularly sauropodomorph dinosaurs (Joyce and Gauthier, 2004; Joyce et al., 2009, 2013a). Aquatic turtle abound in freshwater aquatic sediments globally following the Middle Jurassic (e.g., Wings et al., 2012). This coincides with the origin of the crown group (Danilov and Parham, 2006; Joyce, 2007; Anquetin, 2012), which is universally optimized in phylogenetic analyses to have originated from an aquatic ancestor. The derived turtle stem lineage is, therefore, clearly terrestrial and a close relationship with marine sauropterygians cannot be corroborated using ecological arguments.

This consensus was somewhat challenged by Odontochelys semitestacea. Li et al. (2008) note that all known specimens of 0 . semitestacea originate from sediments that were deposited in a 
small marine basin surrounded by land from three sides and known to contain terrestrial floras and faunas. All known specimens, therefore, could have easily washed in from the nearby coasts. Li et al. (2008) furthermore noted that the shortened hands of 0 . semitestacea are equivalent in length to modern turtles living in "stagnant or small bodies of water," but failed to emphasize that this category of turtles implies swampy, freshwater habitats, not coastal marine waters (Joyce and Gauthier, 2004). Although Li et al. (2008) at no point indicate marine habitat preference for this taxon, the image of 0 . semitestacea as a marine proto-turtle has nevertheless been burned into the collective mind of the scientific community through countless reconstructions of this taxon portraying $O$. semitestacea as an agile swimmer of open marine waters (e.g., Benton et al., 2013). However, this habitat preference is highly unlikely for this taxon, because neither its stiffened torso nor its reduced limbs and tail would have allowed effective propulsion in marine settings.

One observation allows me to even question the freshwater aquatic habitat preferences for 0 . semitestacea. I agree with $\mathrm{Li}$ et al. (2008) that this taxon plots with various "swampy" taxa in the ternary diagram of Joyce and Gauthier (2004), but this diagram is based on modern turtles with a phalangeal count of 2-3-3-3-3 or less. The primary difference between terrestrial turtles and aquatic turtles is the relative length of the proximal phalanges, because turtles that walk on dry land need short phalanges to allow rollover, whereas aquatic turtles require elongate phalanges for the formation of effective flippers or paddles (Joyce and Gauthier, 2004). The unguals are typically elongate in both groups to support the claws. Unlike all testudinates, 0 . semitestacea still possess a primitive phalangeal count of 2-3-4-4-3 (Li et al., 2008), but the proximal phalanges are notably robust and shortened, as in extant terrestrial turtles. This taxon is therefore pushed into the semi-aquatic habitat zone in the ternary diagram of Joyce and Gauthier (2004) by its plesiomorphic phalangeal count, not because it has the long phalanges characteristic of aquatic turtles.

In conclusion, Odontochelys semitestacea was likely a fully terrestrial stem turtle, and, at most, an inhabitant of swampy freshwater environments. This conclusion does not help resolve the origin of turtles in any detail, as most groups of amniotes have a strong terrestrial signal in the Permian and Triassic, including archosaurs and Eunotosaurus africanus. However, the potentially freshwater aquatic habitat preferences of 0 . semitestacea should not tacitly be used as evidence in favor of relationships with marine sauropterygians.

\section{DISCUSSION AND CONCLUSIONS}

The origin of turtles has puzzled paleontologists for more than 100 years, because the fossil record had failed to provide recognizable intermediate forms beyond the Late Triassic Proganochelys quenstedti (Gaffney, '90). The origin of birds had posed a similar problem for over a century, because the stem lineage of birds was primarily filled by the Late Jurassic taxon Archaeopteryx lithographica. This taxon displays enough characters to clearly link it with crown birds (e.g., feathers, wings, fused clavicles, reduced fingers), but also numerous symplesiomorphies that highlight its reptilian affiliations (e.g., teeth, long tail, gastralia; Huxley, '68). A lack of additional fossils, however, provided enough room for an acrimonious debate regarding the precise placement of birds within Archosauria (e.g., Ostrom, '76; Martin et al., '80; Chatterjee, '91). This lack of transitional fossils furthermore cemented the idea that most avian characters originated in parallel with one another in direct relationship with flight (e.g., Feduccia, '96).

Over the course of the last 20 years, an astounding sample of intermediate forms has identified birds as highly derived theropod dinosaurs beyond all reasonable doubt (Zhou, 2004). Although the debate continues regarding the precise interrelationships of various theropod groups (e.g., Xu et al., 2011; Godefroit et al., 2013), the primary steps within this transitional series are now clear. One of the most surprising realizations of this research program has been that the majority of characters historically associated with birds and flight (e.g., various types of feathers, hollow bones, furculum, avian breathing) originated one by one over the course of tens of millions of years deep within the theropod clade (e.g., Xu et al., 2001; Schachner et al., 2009; Foth et al., 2014) and were not developed in concert with flight. This conclusion at the same time provides the most convincing support for the theropod origin of birds, because birds are linked to theropods by a long list of synapomorphies that were previously though to be unique to birds.

In the older literature, turtles were variously allied with Eunotosaurus africanus (Watson, '14), plesiosaurs (Moodie, '08), placodonts (Jaeckel, '02), “cotylosaurs” (Cope, '96), temnospondyls (Vallén, '42), pareiasaurs (Gregory, '46), diadectids (Olson, '47), and captorhinomorphs (Carroll, '69), but most of these hypotheses were support by isolated characters and lacked a global perspective. Early cladistic hypotheses on turtle origins placed turtles as sister to captorhinids (Gaffney and McKenna, '79; Gaffney and Meylan, '88; Gauthier et al., '88a), but larger, computer-assisted analyses hypothesized a sister group relationship to "anapsid" procolophonids (Reisz and Laurin, '91; Laurin and Reisz, '95) or pareiasaurs (Lee, '93, '97), "parapsid” sauropterygians (Rieppel and deBragga, '96; deBraga and Rieppel, '97), or “parapsid/diapsid” lepidosaurs (Müller, 2004). Interestingly, all modern analysis excluded E. africanus a priori, even though this taxon had consistently been listed as sister to turtles in standard paleontological textbooks and classifications throughout much of the century (e.g., Huene, '56; Romer, '56; Carroll, '88).

One reason why none of these hypotheses fully convinced the systematic community is because turtles remained highly apomorphic (Carroll, 2013) and because none of the characters 
that are truly unique to turtle (i.e., reduced count of notably elongate dorsal vertebrae that decrease in length from anterior to posterior; articulation of the dorsal ribs with two adjacent vertebrae along a single process; plastron formed from the interclavicle, clavicles, and gastralia in interaction with the dermis; carapace formed by the ribs, vertebrae, and cleithra in interaction with the dermis; turtle respiration; the putatively unique placement of the shoulder girdle relative to the rib cage) are to be found among potential sister groups. Conversely, even though multiple groups of shelled amniotes are present in the Triassic that could potentially be the sister of turtles, such as Henodus chelyops (Huene, '36) or Sinosaurosphargis yunguiensis (Li et al., 2011), close analysis of the "shells" of these taxa (Westphal, '76; Li et al., 2011) and character optimization (deBraga and Rieppel, '97; Li et al., 2011; Neenan et al., 2013) universally reject homology of these shells with those of turtles.

The Eunotosaurus hypothesis is different from all previous hypotheses regarding the origin of turtles because it is based on an impressive set of characters that were previously thought to be unique to turtles that originated one by one over the course of tens of millions of years. The most convincing aspect of the Eunotosaurus hypothesis is that these characters do not originate in parallel with the turtle shell, but rather in sequence as exaptations (Gould and Vrba, '82) millions of years prior to the formation of a full shell and for reasons not related to the formation of the shell. In this regard, our understanding of the origin of turtles is now finally converging on progress reached regarding the origin of birds. Although future finds are expected to reveal additional nuances and homoplastic complications, the overall evolutionary frame now seems to be set.

The most recent comprehensive reviews of the molecular ( $\mathrm{Lu}$ et al., 2013) and morphological (Lee, 2013) data reveal that neither source can resolve the placement of turtles within Amniota with confidence. This is consistent with the divergence of the three primary lineages of reptiles (Testudines, Lepidosauria, Archosauria) within little time in the late Paleozoic. Eunotosaurus africanus solves many questions regarding the origin of turtles, in particular the origin of the turtle shell, but it does not resolve the placement of turtles within the amniote system. Future work will therefore have to focus on better understanding the anatomy of E. africanus, in particular its cranial anatomy, and in revising the phylogenetic relationships of Late Paleozoic amniotes. Regardless of the outcome of this debate, the hopeful monster has left the building.

\section{ACKNOWLEDGMENTS}

I would like to thank Jacqueline Moustakas-Verho for the invitation to present a comprehensive paleontological viewpoint on the origin of turtles. I am indebted to numerous friends and colleagues who helped me form some of the opinions presented herein through meaningful papers and conversations, in particular Jérémy Anquetin, Igor Danilov, Jacques Gauthier, Tyler Lyson, Jim Parham, Márton Rabi, Torsten Scheyer, Rainer
Schoch, Juliana Sterli, Rachel Warnock, and Ingmar Werneburg. Two anonymous reviewers provided insightful comments that greatly helped improve the quality of this manuscript.

\section{LITERATURE CITED}

Abramyan J, Badenhorst D, Biggar KK, et al. 2013. The western painted turtle genome, a model for the evolution of extreme physiological adaptations in a slowly evolving lineage. Genome Biol 14:R28.

Anquentin J. 2012. Reassessment of the phylogenetic interrelationships of basal turtles (Testudinata). J Syst Palaeontol 10:3-45.

Benton MJ, Wills MA, Hitchin R. 2000. Quality of the fossil record through time. Nature 403:534-537.

Benton MJ, Zhang OY, Hu SX, et al. 2013. Exceptional vertebrate biotas from the Triassic of China, and the expansion of marine ecosystems after the Permo-Triassic mass extinction. Earth Sci Rev 123:199-243.

Bhullar BAS, Bever GS. 2009. An archosaur-like laterosphenoid in early turtles (Reptilia: Pantestudines). Breviora 518:1-11.

Brainerd EL, Owerkowicz T. 2006. Functional morphology and evolution of aspiration breathing in tetrapods. Respir Physiol Neurobiol 154:73-78.

Broom R. 1924. On the classification of the reptiles. Bull Am Mus Nat Hist 51:39-65.

Burke AC. 1989. Development of the turtle carapace: implications for the evolution of a novel bauplan. J Morphol 199:363-378.

Cao Y, Waddell P, Okada N, et al. 1998. The complete mitochondrial DNA sequence of the shark Mustelus manazo: evaluating rooting contradictions to living bony vertebrates. Mol Biol Evol 15:1637-1646.

Cao Y, Sorenson MD, Kumazawa Y, et al. 2000. Phylogenetic position of turtles among amniotes: evidence from mitochondrial and nuclear genes. Gene 259:139-148.

Carroll RL. 1969. A Middle Pennsylvanian captorhinomorph, and the interrelationships of primitive reptiles. J Paleontol 43:151-170.

Carroll RL. 1988. Vertebrate paleontology and evolution. New York: Freeman.

Carroll RL. 2009. Gene Gaffney and the evolutionary history of turtles. In: Braman DR, editor. Abstract and program, turtle symposium, October 17-18 2009. Drumheller: Royal Tyrell Museum.

Carroll RL. 2013. Problems of the ancestry of turtles. In: Brinkman BD, Holroy PA, Gardner JD, editors. Morphology and evolution of turtles. New York: Springer. p 19-36.

Caspers GJ, Reinders GJ, Leunissen JAM, et al. 1996. Protein sequences indicate that turtles branched off from the Amniote tree after mammals. J Mol Evol 42:580-586.

Chatterjee S. 1991. Cranial anatomy and relationships of a new Triassic bird from Texas. Phil Trans R Soc Lond B 332:277-342.

Chiari Y, Cahais V, Galtier N, et al. 2012. Phylogenomic analyses support the position of turtles as the sister group of birds and crocodiles (Archosauria). BMC Biol 10:65.

Cope ED. 1896. The ancestry of the Testudinata. Am Nat 1896:398-400.

Cotton JA, Page RDM. 2002. Going nuclear: gene family evolution and vertebrate phylogeny reconciled. Proc R Soc London B 269:1555-1561. 
Cox CB. 1969. The problematic Permian reptile Eunotosaurus. Bull $\mathrm{Br}$ Mus Nat Hist 18:165-196.

Crawford NG, Faircloth BC, McCormack JE. 2012. More than 100 ultraconserved elements provide evidence that turtles are the sister group of archosaurs. Biol Lett 8:783-786.

deBeer GS. 1937. The development of the vertebrate skull. Oxford: Clarendon Press.

deBraga M, Rieppel 0. 1997. Reptile phylogeny and the affinities of turtles. Zool J Linn Soc 120:281-354.

de Pinna MGG. 1991. Concepts and tests of homology in the cladistic paradigm. Cladistics 7:367-394.

Dilkes DW. 1998. The early Triassic rhynchosaur Mesosuchus browni and the interrelationships of basal archosauromorph reptiles. Phil Trans R Soc Lond B 353:501-541.

Donoghue MJ, Doyle JA, Gauthier J, et al. 1989. The importance of fossils in phylogeny reconstruction. Annu Rev Ecol Syst 20:431-460.

Felsenstein J. 1978. Cases in which parsimony or compatibility methods will be positively misleading. Syst Zool 27:401-410.

Field DJ, Gauthier JA, King BL, et al. 2014. Toward consilience in reptile phylogeny: miRNAs support an archosaur, not lepidosaur, affinity for turtles. Evol Dev 16:189-196.

Fong JJ, Brown JM, Fujita MK, et al. 2012. Phylogenomic approach to vertebrate phylogeny supports a turtle-archosaur affinity and a possible paraphyletic Lissamphibia. PLoS ONE 7:e48990.

Foth C, Tischlinger H, Rauhut OWM. 2014. New specimen of Archaeopteryx provides insights into the evolution of pennaceous feathers. Nature 511:79-82.

Feduccia A. 1996. The origin and evolution of birds. New Haven, London: Yale University Press.

Gaffney ES. 1990. The comparative osteology of the Triassic turtle Proganochelys. Bull Am Mus Nat Hist 194:1-263.

Gaffney ES. 1996. The postcranial morphology of Meiolania platyceps and a review of the Meiolaniidae. Bull Am Mus Nat Hist 229:1-165.

Gaffney ES, McKenna MC. 1979. A Late Permian captorhinid from Rhodesia. Am Mus Novitates 2688:1-15.

Gaffney ES, Meylan PA. 1988. A phylogeny of turtles. In: Benton MJ, editor. The phylogeny and classification of the tetrapods. Oxford: Clarendon Press. p 157-219.

Gaffney ES, Meylan PA, Wyss AR. 1991. A computer assisted analysis of the relationships of the higher categories of turtles. Cladistics 7:313-335.

Gaffney ES, Rich TH, Vickers-Rich P, et al. 2007. Chubutemys, a new eucryptodiran turtle from the Early Cretaceous of Argentina, and the relationships of Meiolaniidae. Am Mus Nov 3599:1-35.

Gardiner BG. 1993. Haematothermia: warm-blooded amniotes. Cladistics 9:369-395.

Gaunt AS, Gans C. 1969. Mechanics of respiration in the snapping turtle. Chelydra serpentina (Linne). J Morphol 128:195-228.

Gauthier JA, Kluge AG, Rowe T. 1988a. The early evolution of the Amniota. In: Benton MJ, editor. The phylogeny and classification of the tetrapods. Oxford: Clarendon Press. p 103-155.
Gauthier J, Kluge AG, Rowe T. 1988b. Amniote phylogeny and the importance of fossils. Cladistics 4:105-209.

Gauthier JA, Kearney M, Maisano JA, Rieppel O, Behlke ADB. 2012. Assembling the squamate tree of life: perspectives from the phenotype and the fossil record. Bull Peabody Mus Nat Hist 53:3308.

Gilbert SF, Loredo GA, Brukman A, et al. 2001. Morphogenesis of the turtle shell: the development of a novel structure in tetrapod evolution. Evol Dev 3:47-58.

Godefroit P, Cau A, Hu DY, et al. 2013. A Jurassic avialan dinosaur from China resolves the early phylogenetic history of birds. Nature 498:359-362.

Goodrich ES. 1930. Studies on the structure and development of vertebrates. London: Macmillan.

Gould SJ, Vrba ES. 1982. Exaptation-a missing term in the science of form. Paleobiol 8:4-15.

Graybeal A. 1998. Is it better to add taxa or characters to a difficult phylogenetic problem. Syst Biol 47:9-17.

Gregory WK. 1946. Pareiasaurs versus placodonts as near ancestors to the turtles. Bull Am Mus Nat Hist 86:275-326.

Hedges SB. 1994. Molecular evidence for the origin of birds. Proc Natl Acad Sci USA 91:2621-2624.

Hedges SB, Poling LL. 1999. A molecular phylogeny of reptiles. Science 283:998-1001.

Hillis DM. 1998. Taxonomic sampling, phylogenetic accuracy, and investigator bias. Syst Biol 47:3-8.

Hirasawa T, Nagashima H, Kuratani S. 2013. The endoskeletal origin of the turtle carapace. Nat Commun 4:2107.

Hirasawa T, Pascual-Anaya J, Kamezaki N, et al. 2014. The evolutionary origin of the turtle shell and its dependence on the axial arrest of the embryonic rib cage. J Exp Biol B Mol Dev Evol. DOI:10.1002/jez.b.22579.

F von Huene. 1936. Henodus chelyops, ein neuer Placodontier. Palaeontographica A 84:99-147.

F von Huene. 1956. Paläontologie und Phylogenie der niederen Tetrapoden. Jena: Fischer.

Hugall AF, Foster R, Lee MSY. 2007. Calibration choice, rate smoothing, and the pattern of tetrapod diversification according to the long nuclear gene RAG-1. Syst Biol 56:543-563.

Huxley TH. 1868. On the animals which are most nearly intermediate between birds and reptiles. Geol Mag 5:357-365.

Iwabe N, Hara Y, Kumazawa Y, et al. 2005. Sister group relationship of turtles to the bird-crocodilian clade revealed by nuclear DNAcoded proteins. Mol Biol Evol 22:810-813.

Jaeckel 0. 1902. Ueber Placochelys n. g. und ihre Bedeutung für die Stammesgeschichte der Schildkröten. N Jb Min Geol Pal 1902:127144.

Jenkins FA. 1970. Anatomy and function of expanded ribs in certain edentates and primates. J Mammal 51:288-301.

Joyce WG. 2007. A phylogeny of Mesozoic turtles. Bull Peabody Mus Nat Hist 48:3-102. 
Joyce WG, Gauthier JA. 2004. Palaeoecology of Triassic stem turtles sheds new light on turtle origins. Proc R Soc B 271:1-5.

Joyce WG, Sterli J. 2012. Congruence, non-homology, and the phylogeny of basal turtles. Act Zool 93:149-159.

Joyce WG, Parham JF, Gauthier JA. 2004. Developing a protocol for the conversion of rank-based taxon names to phylogenetically defined clade names, as exemplified by turtles. J Paleontol 78:9891013.

Joyce WG, Jenkins FA, Rowe T. 2006. The presence of cleithra in the basal turtle Kayentachelys aprix. Fossil Turtle Res 1:93-103.

Joyce WG, Lucas SG, Scheyer TM, et al. 2009. A thin-shelled reptile from the Late Triassic of North America and the origin of the turtle shell. Proc R Soc B 276:507-513.

Joyce WG, Schoch RR, Lyson TR. 2013a. The girdles of the oldest fossil turtle, Proterochersis robusta, and the age of the turtle crown. BMC Evol Biol 13:266.

Joyce WG, Werneburg I, Lyson TR. 2013b. The hooked element in the pes of turtles (Testudines): a global approach to exploring primary and secondary homology. J Anat 223:421-441.

Joyce WG, Sterli J, Chapman SD. 2014. The skeletal morphology of the solemydid turtle Naomichelys speciosa from the early Cretaceous of Texas. J Paleontol 88:1257-1287.

Kumazawa Y, Nishida M. 1999. Complete mitochondrial DNA sequences of the green turtle and blue-tailed mole skink: statistical evidence for archosaurian affinity of turtles. Mol Biol Evol 16:784792.

Kuratani S, Kuraku S, Nagashima H. 2011. Evolutionary developmental perspective for the origin of turtles: the folding theory for the shell based on the developmental nature of the carapacial ridge. Evol Dev 13:1-14.

Laurin M, Reisz RR. 1995. A re-evaluation of early amniote phylogeny. Zool J Linn Soc 113:165-223.

Lecointre G, Philippe H, Le HLV, et al. 1993. Sampling has a major impact on phylogenetic inference. Mol Gen Evol 2:205-224.

Lee MSY. 1993. The origin of the turtle body plan: bridging a famous morphological gap. Science 261:1716-1720.

Lee MSY. 1997. Pareiasaur phylogeny and the origin of turtles. Zool J Linn Soc 120:197-280.

Lee MSY. 2013. Turtle origins: insights from phylogenetic retrofitting and molecular scaffolds. J Evol Biol 26:2729-2738.

Li C, Wu XC, Rieppel O, et al. 2008. Ancestral turtle from the late Triassic of southwestern China. Nature 456:497-501.

Li C, Rieppel 0, Wu XC, et al. 2011. A new Triassic marine reptile from southwestern China. J Vert Paleontol 31:303-312.

Lu B, Yang W, Dai Q, et al. 2013. Using genes as characters and a parsimony analysis to explore the phylogenetic position of turtles. PLOS ONE 8:e79348.

Lyson TR, Joyce WG. 2012. Evolution of the turtle bauplan: the topological relationship of the scapula relative to the ribcage. Biol Lett 8:1028-1031.

Lyson TR, Bever GS, Bhullar BAS, et al. 2010. Transitional fossils and the origin of turtles. Biol Lett 6:830-833.
Lyson TR, Sperling EA, Heimberg AM, et al. 2012. MicroRNAs support a turtle+ lizard clade. Biol Lett 8:104-107.

Lyson TR, Bever GS, Scheyer TM, et al. 2013a. Evolutionary origin of the turtle shell. Curr Biol 23:1113-1119.

Lyson TR, Bhullar BAS, Bever GS, et al. 2013b. Homology of the enigmatic nuchal bone reveals novel reorganization of the shoulder girdle in the evolution of the turtle shell. Evol Dev 15:317-325.

Lyson TR, Schachner ER, Botha-Brink J, et al. 2014. Origin of the unique ventilator apparatus of turtles. Nat Comm 5:5211. DOI:10.1038/ncomms6211.

Mannen H, Li SSL. 1999. Molecular evidence for a clade of turtles. Mol Phylogenet Evol 13:144-148.

Martin LD, Stewart JD, Whetstone KN. 1980. The origin of birds: structure of the tarsus and teeth. Auk 97:86-93.

Modesto SP, Scott DM, Reisz RR. 2009. A new parareptile with temporal fenestration from the Middle Permian of South Africa. Can J Earth Sci 46:9-20.

Moodie RL. 1908. The relationship of the turtles and plesiosaurs. Kansas Univ Sci Bull 4:319-327.

Müller J. 2003. Early loss and multiple return of the lower temporal arcade in diapsid reptiles. Naturwissenschaften 90:473-476.

Müller J. 2004. The relationships among diapsid reptiles and the influence of taxon selection. In: Arratia G, Cloutier R, Wilson VH, editors. Recent advances in the origin and early radiation of vertebrates. Munich: Dr Friedrich Pfeil. p 379-408.

Müller J, Tsuji LA. 2007. Impedance-matching hearing in Paleozoic reptiles: evidence of advanced sensory perception at an early stage of amniote evolution. PloS ONE 2:e889.

Müller J, Scheyer TM, Head JJ, et al. 2010. Homeotic effects, somitogenesis and the evolution of vertebral numbers in recent and fossil amniotes. PNAS 107:2118-2123.

Nagashima H, Kuraku S, Uchida K, et al. 2007. On the carapacial ridge in turtle embryos: its developmental origin, function and the chelonian body plan. Development 134:2219-2226.

Nagashima H, Sugahara F, Takechi M, et al. 2009. Evolution of the turtle body plan by the folding and creation of new muscle connections. Science 325:193-196.

Nagashima H, Kuraku S, Uchida K, et al. 2012. Body plan of turtles: an anatomical, developmental and evolutionary perspective. Anat Sci Int 87:1-13.

Nagashima H, Kuraku S, Uchida K, et al. 2013. Origin of the turtle body plan: the folding theory to illustrate turtle-specific developmental repatterning. In: Brinkman BD, Holroyd PA, Gardner JD, editors. Morphology and evolution of turtles. New York: Springer. p 37-50.

Neenan JM, Klein N, Scheyer TM. 2013. European origin of placodont marine reptiles and the evolution of crushing dentition in Placodontia. Nat Comm 4:1621.

Nicholls H. 2005. Ancient DNA comes of age. PLOS Biol 3:e56.

Nishihara H, Okada N, Hasegawa M. 2007. Rooting the eutherian tree: the power and pitfalls of phylogenomics. Genome Biol 8:R199.

Olson EC. 1947. The family Diadectidae and its bearing on the classification of reptiles. Fieldiana Geol 11:1-53. 
Osborn HF. 1903. The reptilian subclasses Diapsida and Synapsida and the early history of the Diaptosauria. Mem Am Mus Nat Hist 1:265270.

Ostrom JH. 1976. Archaeopteryx and the origin of birds. Biol J Linn Soc 8:91-182.

Parsons TS, Williams EE. 1961. Two Jurassic turtle skulls: a morphological study. Bull Mus Comp Zool 125:43-107.

Patterson C. 1977. Cartilage bones, dermal bones and membrane bones, or the exoskeleton versus the endoskeleton. In: Andrews SM, Miles $R S$, Walker $A D$, editors. Problems in vertebrate evolution. London: Academic Press. p 77-121.

Philippe H, Zhou Y, Brinkmann H, Rodrigue N, Delsuc F. 2005. Heterotachy and long-branch attraction in phylogenetics. BMC Evol Biol 5:50.

Philippe $H$, Brinkmann $H$, Lavrov DV, et al. 2011. Resolving difficult phylogenetic questions: why more sequences are not enough. PLoS Biol 9:e1000602.

Platz JE, Conlon JM. 1997 ...and turn back again. Nature 389:246.

Pollock DD, Eisen JA, Doggett NA, et al. 2000. A case for evolutionary genomics and the comprehensive examination of sequence biodiversity. Mol Biol Evol 17:1776-1788.

Rannala B, Huelsenbeck JP, Yang Z, et al. 1998. Taxon sampling and the accuracy of large phylogenies. Syst Biol 47:702-710.

Reisz RR, Laurin M. 1991. Owenetta and the origin of turtles. Nature 349:324-326.

Rest JS, Ast JC, Austin CC, et al. 2003. Molecular systematics of primary reptilian lineages and the tuatara mitochondrial genome. Mol Phylogenet Evol 29:289-297.

Rieppel 0. 2000a. Turtles as diapsid reptiles. Zool Scr 29:199-212.

Rieppel 0.2000b. Paraplacodus and the phylogeny of the Placodontia (Reptilia: Sauropterygia). Zool J Linn Soc 130:635-659.

Rieppel 0. 2001. Turtles as hopeful monsters. BioEssays 23:987-991.

Rieppel 0, deBragga M. 1996. Turtles as diapsid reptiles. Nature 384:453-455.

Rieppel 0, Reisz RR. 1999. The origin and evolution of turtles. Annu Rev Ecol Syst 30:1-22.

Romer AS. 1956. Osteology of the reptiles. Chicago: University of Chicago Press.

Salichos L, Rokas A. 2013. Inferring ancient divergences requires genes with strong phylogenetic signals. Nature 497:327-331.

Schachner ER, Lyson TR, Dodson P. 2009. Evolution of the respiratory system in nonavian theropods: evidence from rib and vertebral morphology. Anat Rec 292:1501-1513.

Shaffer HB, Minx P, Warren DE, et al. 2013. The western painted turtle genome, a model for the evolution of extreme physiological adaptations in a slowly evolving lineage. Genome Biol 14:R28.

Scheyer TM, Sander PM. 2007. Shell bone histology indicates terrestrial palaeoecology of basal turtles. Proc Biol Soc B 274:1885-1893.

Scheyer TM, Brüllmann B, Sánchez-Villagra MR. 2008. The ontogeny of the shell in side-necked turtles, with emphasis on the homologies of costal and neural bones. J Morphol 269:1008-1021.
Seeley H. 1892. On a new reptile from Welte Vreden (Beaufort West) Eunotosaurus africanus (Seeley). O J Geol Soc 48:583-585.

Shedlock AM, Botka CW, Zhao S, et al. 2007. Phylogenomics of nonavian reptiles and the structure of the ancestral amniote genome. Proc Nat Acad Sci USA 104:2767-2772.

Shen XX, Liang D, Wen JZ, et al. 2011. Multiple genome alignments facilitate development of NPCL markers: a case study of tetrapod phylogeny focusing on the position of turtles. Mol Biol Evol 28:3237-3252.

Starck D. 1955. Embryologie. Stuttgart: Georg Thieme.

Sterli J, de la Fuente MS, Guillermo SR, Rougier W. 2007. Anatomy and relationships of Palaeochersis talampayensis, a Late Triassic turtle from Argentina. Palaeontogr A 281:1-61.

Sterli J, Pol D, Laurin M. 2013. Incorporating phylogenetic uncertainty on phylogeny-based palaeontological dating and the timing of turtle diversification. Cladistics 29:233-246.

Strimmer K, von Haeseler A. 1996. Quartet Puzzling: a quartet maximum-likelihood method for reconstructing tree topologies. Mol Biol Evol 13:964-969.

Thomson RC, Plachetzki DC, Mahler DL, Moore BR. 2014. A critical appraisal of the use of microRNA data in phylogenetics. Proc Natl Acad Sci 111:E3659-E3668.

Tsuji LA, Müller J. 2009. Assembling the history of the Parareptilia: phylogeny, diversification, and a new definition of the clade. Fossil Record 12:71-81.

Tsuji LA, Müller J, Reisz RR. 2010. Microleter mckinzieorum gen. et sp. nov. from the Lower Permian of Oklahoma: the basalmost parareptile from Laurasia. J Syst Paleontol 8:245-255.

Tsuji LA, Müller J, Reisz RR. 2012. Anatomy of Emeroleter levis and the phylogeny of the nycteroleter parareptiles. J Vert Paleontol 32:4567.

Tzika AC, Helaers R, Schramm G, et al. 2011. Reptilian-transcriptome v1.0, a glimpse in the brain transcriptome of five divergent Sauropsida lineages and the phylogenetic position of turtles. EvoDevo 2:19.

Vallén E. 1942. Beitrage zur Kenntnis der Ontogenie und der vergleichenden Anatomie des Schildkrotenpanzers. Act Zool 23:1127.

Wang Z, Pascual-Anaya J, Zadissa A, et al. 2013. The draft genomes of soft-shell turtle and green sea turtle yield insights into the development and evolution of the turtle-specific body plan. Nat Genet 45:701-706.

Watson DMS. 1914. Eunotosaurus africanus Seeley, and the ancestry of the Chelonia. Proc Zool Soc Lond 1914:1011-1020.

Werneburg I, Hinz JK, Gumpenberger M, et al. 2014. Modeling neck mobility in fossil turtles. J Exp Biol B Mol Dev Evol. DOI:10.1002/jez. b.22557.

Westphal F. 1976. The dermal armour of some Triassic placodont reptiles. In: Bellairs $A, C o x C B$, editors. Morphology and biology of reptiles. London: Academic Press. p 31-41.

Williston SW. 1917. The phylogeny and classification of reptiles. Contrib Walker Mus 2:61-71. 
Wings 0 , Rabi M, Schneider JW, et al. 2012. An enormous Jurassic turtle bone bed from the Turpan Basin of Xinjiang. China. Naturwissenschaften 99:925-935.

Xu X, Zhou ZH, Prum R. 2001. Branched integumental structures in Sinornithosaurus and the origin of feathers. Nature 410:200-204. Xu X, You H, Han F. 2011. An Archaeopteryx-like theropod from China and the origin of Avialae. Nature 475:465-470.
Zangerl R. 1939. The homology of the shell elements in turtles. J Morph 65:383-409.

Zardoya R, Meyer A. 1998. Complete mitochondrial genome suggests diapsid affinities of turtles. Proc Natl Acad Sci 95:14226-14231.

Zhou Z. 2004. The origin and early evolution of birds: discoveries, disputes, and perspectives from fossil evidence. Naturwissenschaften 91:455-471. 